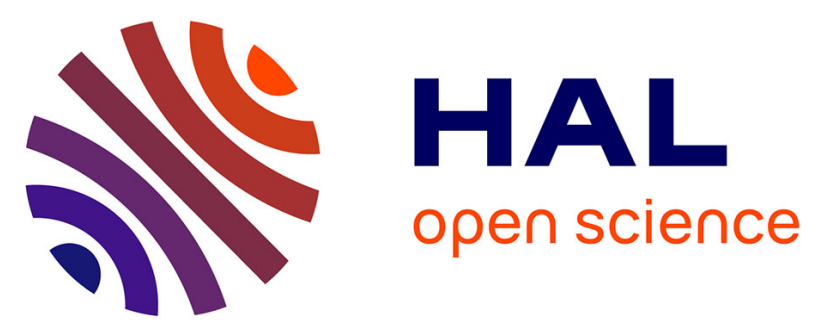

\title{
In situ synchrotron analysis of lattice rotations in individual grains during stress-induced martensitic transformations in a polycrystalline CuAlBe shape memory alloy
}

Sophie Berveiller, Benoît Malard, Jonathan Wright, Etienne Patoor, Guillaume Geandier

\section{To cite this version:}

Sophie Berveiller, Benoît Malard, Jonathan Wright, Etienne Patoor, Guillaume Geandier. In situ synchrotron analysis of lattice rotations in individual grains during stress-induced martensitic transformations in a polycrystalline CuAlBe shape memory alloy. Acta materalia, 2011, 59 (9), pp.3636-3645. 10.1016/j.actamat.2011.02.037 . hal-01195642

\section{HAL Id: hal-01195642 \\ https://hal.science/hal-01195642}

Submitted on 8 Sep 2015

HAL is a multi-disciplinary open access archive for the deposit and dissemination of scientific research documents, whether they are published or not. The documents may come from teaching and research institutions in France or abroad, or from public or private research centers.
L'archive ouverte pluridisciplinaire HAL, est destinée au dépôt et à la diffusion de documents scientifiques de niveau recherche, publiés ou non, émanant des établissements d'enseignement et de recherche français ou étrangers, des laboratoires publics ou privés. 


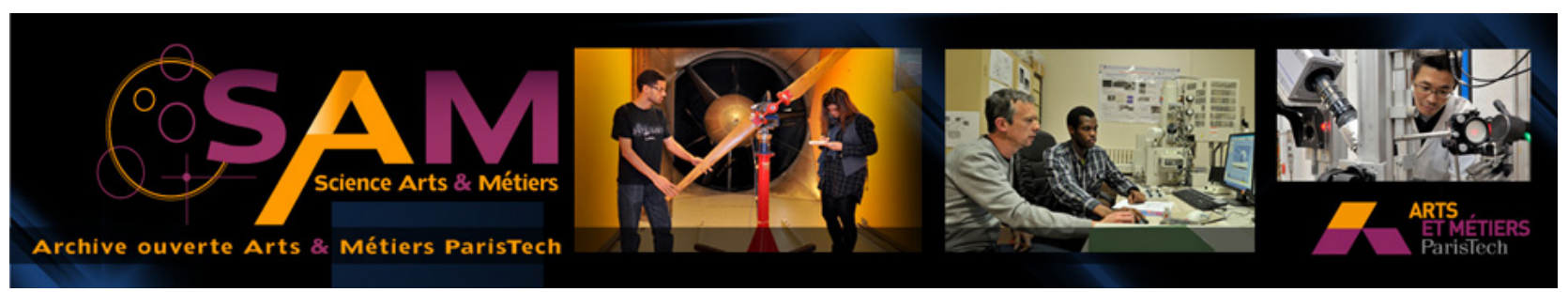

\section{Science Arts \& Métiers (SAM)}

is an open access repository that collects the work of Arts et Métiers ParisTech researchers and makes it freely available over the web where possible.

This is an author-deposited version published in: http://sam.ensam.eu

Handle ID: .http://hdl.handle.net/10985/9943

\section{To cite this version :}

Sophie BERVEILLER, Benoît MALARD, Jonathan WRIGHT, Etienne PATOOR, Guillaume GEANDIER - In situ synchrotron analysis of lattice rotations in individual grains during stressinduced martensitic transformations in a polycrystalline CuAlBe shape memory alloy - Acta materalia - Vol. 59, n9, p.3636-3645 - 2011 


\title{
In situ synchrotron analysis of lattice rotations in individual grains during stress-induced martensitic transformations in a polycrystalline $\mathrm{CuAlBe}$ shape memory alloy
}

\author{
S. Berveiller ${ }^{\mathrm{a}, *}$, B. Malard ${ }^{\mathrm{a}}$, J. Wright $^{\mathrm{b}}$, E. Patoor ${ }^{\mathrm{a}}$, G. Geandier $^{\mathrm{b}}$ \\ ${ }^{a}$ Laboratory of Physics and Mechanics of Materials, Arts et Métiers ParisTech, 4 rue Augustin Fresnel, 57078 Metz, France \\ ${ }^{\mathrm{b}}$ European Synchrotron Radiation Facility, 38043 Grenoble, France
}

\begin{abstract}
Two synchrotron diffraction techniques, three-dimensional X-ray diffraction and Laue microdiffraction, are applied to studying the deformation behaviour of individual grains embedded in a $\mathrm{Cu}_{74} \mathrm{Al}_{23} \mathrm{Be}_{3}$ superelastic shape memory alloy. The average lattice rotation and the intragranular heterogeneity of orientations are measured during in situ tensile tests at room temperature for four grains of mean size $\sim 1 \mathrm{~mm}$. During mechanical loading, all four grains rotate and the mean rotation angle increases with austenite deformation. As the martensitic transformation occurs, the rotation becomes more pronounced, and the grain orientation splits into several sub-domains: the austenite orientation varies on both sides of the martensite variant. The mean disorientation is $\sim 1^{\circ}$. Upon unloading, the sub-domains collapse and reverse rotation is observed.
\end{abstract}

\section{Introduction}

The understanding of complex relations between microstructure and macroscopic properties in materials leads to better use of materials and development of innovative applications. Shape memory alloys (SMA) are perhaps one of the best examples of the importance of such an understanding. These materials can recover their original shape after undergoing deformation of several per cent. The recovery which occurs upon heating is termed shape memory effect, while on unloading it is superelasticity. These remarkable properties are related to the martensitic transformation. Many studies have been devoted to these phenomena in the last 40 years [1], and a growing number of industrial and commercial applications are based on these phenomena. Among the most successful applications are vascular stents [2] and dental files [3].

The martensitic transformation can be studied on several length scales. At the crystallographic lattice scale, a large deviatoric strain is associated with the transition from high-temperature austenite to low-temperature martensite. On a longer length scale, strain incompatibilities between martensite and austenite domains are responsible for the occurrence of stacking faults and microtwins, leading to the formation of characteristic martensitic microstructures. The morphology of austenite grains with intragranular martensite variants also defines a characteristic internal length of the structure. Some aspects of these features are already taken into account in modelling, as in the work of Bhattacharya and Kohn [4], in phase field approaches [5] or in scale transition schemes [6,7], but several of these key characteristics are still unclear, such as the strain incompatibilities between crystal lattices of austenite and martensite phases and lattice rotations. Few attempts have 
been made experimentally to relate these different microstructural levels to the observed material behaviour $[8,9]$.

Experimental difficulties in accessing local information on polycrystals are responsible for this lack of knowledge. In SMA, single crystal analysis has delivered a great deal of useful information furthering the understanding of interfacial motions between parent and product phases, for both uniaxial loading and temperature changes [10-14]. Unfortunately, these results cannot be easily extended to martensitic transformation in polycrystalline materials. Strain incompatibilities occurring at grain boundaries and stress transfer between transforming grains strongly influence the transformation kinetics in polycrystals [4]. As a consequence, the macroscopic behaviour differs strongly between polycrystals and single crystals. Micromechanical scale transition models have been developed to account for these differences. They predict the occurrence of large intergranular strain incompatibilities [6], but few experimental data are available at this length scale to validate these results. Broadening of X-ray diffraction peaks of the austenite phase was observed during the transformation in a $\mathrm{Cu}-\mathrm{Al}-\mathrm{Be}$ polycrystal with coarse grains [9] and in a $\mathrm{Cu}-\mathrm{Al}-\mathrm{Zn}-\mathrm{Mn}$ polycrystal with small grains [15] and was ascribed to the development of strain incompatibilities during the transformation [9]. The reverse process was observed upon unloading, while martensite transforms back to austenite [15]. Such preliminary results advocate the development of an experimental methodology allowing observations of micro-mechanisms occurring during the martensitic transformation by coupling different analysis techniques and in situ characterization of material behaviour. In this context, "in situ" means microstructural analysis performed during thermomechanical loading.

Synchrotron diffraction techniques give volume information and allow microstructural analysis at different length scales. To the authors' knowledge two recent techniques, namely three-dimensional X-ray diffraction (3DXRD) microscopy and Laue microdiffraction, have been applied to the analysis of phase transformation in steels under cooling $[16,17]$ or to the study of plasticity in metallic alloys $(\mathrm{Cu}, \mathrm{Al})[18,19]$, but they have never been applied to characterizing martensitic transformation in SMA, and these techniques have not been used together to reach a global understanding of the transformation mechanism. This work presents a multiscale analysis com- bining different experimental techniques as tensile tests to characterize the overall behaviour of the sample, synchrotron diffraction techniques for microstructural analysis and optical microscopy to observed the degree of transformation in a $\mathrm{Cu}_{74} \mathrm{Al}_{23} \mathrm{Be}_{3} \mathrm{SMA}$. Following basic information on both techniques (3DXRD and Laue microdiffraction techniques), the results are presented: the average rotations of the grains as well as heterogeneities within the grain are discussed.

\section{Experimental methods}

In order to characterize microstructural features related to superelastic behaviour, a 3DXRD microscope was used to analyse the behaviour of each individual grain embedded inside the polycrystalline material. Then Laue microdiffraction was performed to achieve a local analysis at the intragranular scale. All measurements were done using an in situ tensile device.

\subsection{Materials}

Copper-based SMA were chosen in this study because grain size is larger in these alloys than in nickel-titanium. This allows easier development for intragranular studies. Among copper-based SMA, $\mathrm{Cu}-\mathrm{Al}-\mathrm{Be}$ alloys present suitable characteristics: a large macroscopic transformation strain and good thermal stability [20]. The weight composition of the alloy studied was $87.8 \%$ copper, $11.6 \%$ aluminium and $0.6 \%$ beryllium, with an expected transformation temperature $M_{\mathrm{s}}$ below room temperature $\left(M_{\mathrm{s}} \approx-115^{\circ} \mathrm{C}\right)$. The samples were solution treated at $800^{\circ} \mathrm{C}$ in the $\beta$ phase, water quenched and annealed at $200{ }^{\circ} \mathrm{C}$ for $1 \mathrm{~h}$ : therefore they were fully austenitic with coarse millimetric grain size at room temperature.

\section{2. $3 D X R D$ microscopy}

This technique is based on the measurement of local crystallographic lattice orientations using a monochromatic beam to get a map of the microstructure; a detailed presentation can be found in Refs. [21-25]. In the present work on beamline ID11 at the European Synchrotron Radiation Facility (ESRF), the energy of incident X-rays

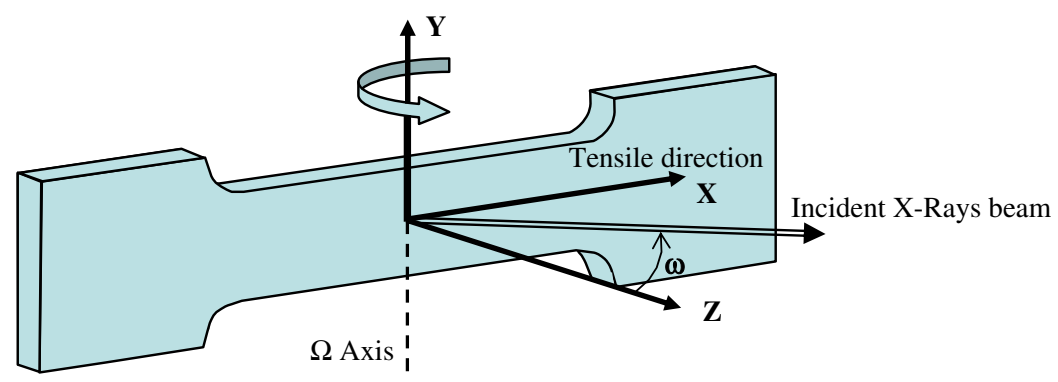

Fig. 1. Definition of sample position and tensile direction with respect to the incident X-rays beam in the 3DXRD microscope on the ESRF ID11 beam line. 
beam is $80 \mathrm{keV}$. The beam size is $200 \times 200 \mu \mathrm{m}$. The sample is mounted in a $25 \mathrm{kN}$ Instron stress-rig adapted to the diffractometer and placed on the $\omega$-rotation stage and a $(x, y, z)$-translation stage. The gage length is $45 \mathrm{~mm}$, the thickness $2 \mathrm{~mm}$ and the width $8 \mathrm{~mm}$. The tensile direction is horizontal and transverse to the beam for $\omega=0^{\circ}$, as shown in Fig. 1. During measurement, the sample rotates around the $\Omega$-axis [26]. Each analysis is composed of a set of 305 pictures. Diffracting grains are characterized by their diffraction vectors measured on the diffraction pattern. These vectors are obtained using the ImageD11 software developed by Wright [27]. A minimum of ten diffraction spots is required to get a grain orientation. The GrainSpotter software developed by Schmidt [28] is used to get the orientation matrix according to the known structure (cell parameters). Inside the sample, grains aligned along the $\omega$ rotation axis diffract. A shift in the diffraction pattern is observed for grains that do not respect this alignment. That produces an error in the determination of the grain orientation matrix. A geometrical correction may be applied when the grain shape is known [29]. Such a correction could not be applied in the present case because there is no information about the grain shape inside the bulk. So, only grains presenting diffraction spots for every value of the $\omega$ angle between $-38^{\circ}$ and $38.25^{\circ}$ are considered, which is grains that stay in the diffracting volume whatever the $\omega$ value. As the mean grain size is $\sim 500 \mu \mathrm{m}$, which is larger than the beam size, very few grains are able to respect this condition: in the present case, there were only four grains.

\subsection{Laue microdiffraction technique}

A Laue microdiffraction set-up was developed at ESRF on the polychromatic BM32 beamline with a $5-25-\mathrm{keV}$ beam energy range. The beam size is $2 \mu \mathrm{m}$ in diameter. Using a scanning step of $3 \mu \mathrm{m}$ to collect the Laue patterns, a $170 \times 170 \mu \mathrm{m}$ surface is mapped. Each map is composed of 3306 pictures. As the beam size is lower than the grain size, only one grain stands in the diffracting volume. Indexing of diffraction patterns is performed using XMAS software [30] based on an algorithm proposed by Chung et al. $[30,31]$. The orientation is computed with an accuracy of $0.1^{\circ}$. In the Laue-diffraction experiment, a homemade tensile machine is used. The maximum load capacity of this machine is $5 \mathrm{kN}$. Sample B is presented in Fig. 2. It was used for the micro-Laue experiment; it has a gage length of $19-\mathrm{mm}$, thickness $1.16 \mathrm{~mm}$ and width $5.76 \mathrm{~mm}$. Owing to experimental constrains, only a small area of the sample located in the centre of a coarse grain can be analysed (see Fig. 2). In addition, the homemade tensile machine used for this experiment was not able to keep the analysis zone at a constant position with respect to the X-ray microbeam. After each loading increment, an optical microscope was used to identify and reposition the analysis zone according to the beam. The XMAS indexing software $[30,31]$ gave the crystalline orientation using Euler angles $(\varphi, \theta, \psi)$. Three orientation maps were then obtained at each loading step, one for each Euler angle.

\section{Experimental results}

\subsection{Orientation at the grain scale: $3 D X R D$ results}

\subsubsection{Average grain rotation}

The overall behaviour is presented Fig. 3. An extensometer is used to capture the deformation. The square dots stand for the 18 measurement points performed on loading and the nine points during unloading. The behaviour is elastic up to $280 \mathrm{MPa}$. At higher stress, stress-induced martensitic transformation takes place. The maximum stress imposed in this experiment is $465 \mathrm{MPa}$ in order to avoid the occurrence of plastic strain [32].

As mentioned in Section 2.2, four grains were followed during the mechanical cycle, named grain 1 to grain 4 . Thanks to their initial crystallographic orientation, the Schmid factor was calculated for the best oriented martensitic variants inside each grain. Grain 2 presents the highest Schmid factor (0.49), whereas grain 1 appears to be less favourably oriented (0.31). Grains 3 and 4 have an intermediate orientation (0.40). Crystallographic orientations and Schmid factor are summarized Table 1.

Fig. 4 plots the evolution of the orientation of the load axis in a stereographic triangle for the four grains upon (a) loading and (b) unloading. Each dot in Fig. 4 corresponds to the mean crystalline orientation of one grain at a given loading step. At each loading point, the measurement uncertainty on the orientation value is estimated as $\pm 0.25^{\circ}$.

Upon loading, all four orientations evolve a relatively large amount. The four grains rotate, each one in a differ-

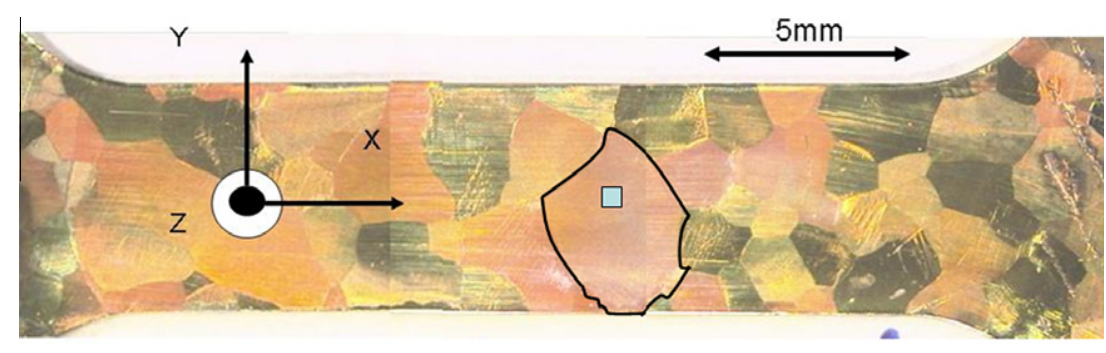

Fig. 2. Overall observation of sample B revealing its coarse granular structure. The square dot shows the domain analysed using the Laue technique. 


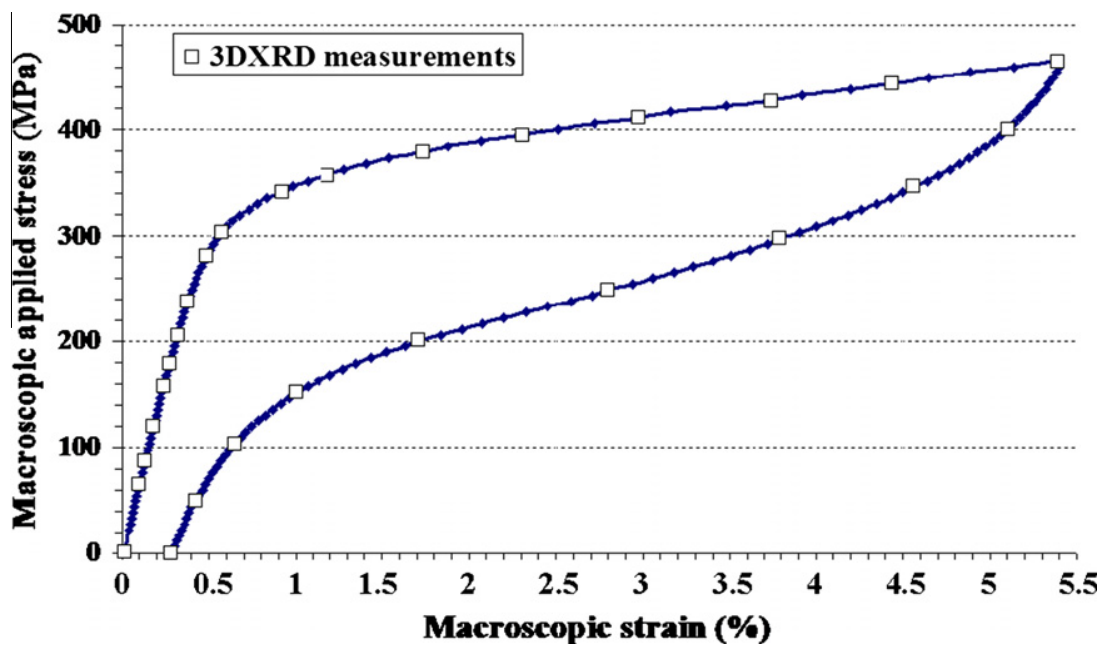

Fig. 3. Stress-strain curve of the CuAlBe superelastic sample recorded during the 3DXRD experiment. Square dots indicate the analysis points.

Table 1

Initial crystallographic orientation and "Schmid" factor of the different grains studied.

\begin{tabular}{|c|c|c|c|c|}
\hline Grain & $\begin{array}{l}\text { Tensile } \\
\text { direction } X \\
\text { [UVW] }\end{array}$ & $\begin{array}{l}\text { Transverse } \\
\text { direction } Y \\
{\left[\mathrm{U}^{\prime} \mathrm{V}^{\prime} \mathrm{W}^{\prime}\right]}\end{array}$ & $\begin{array}{l}\text { Normal } \\
\text { direction } Z \\
{[\text { HKL }]}\end{array}$ & $\begin{array}{l}\text { Schmid } \\
\text { factor }\end{array}$ \\
\hline 1 & $\begin{array}{l}{[\overline{0.12} ; 0.86 ;} \\
0.49]\end{array}$ & {$[0.03 ; \overline{0.50} ; 0.87]$} & $\begin{array}{l}(0.99 ; 0.12 ; \\
0.03)\end{array}$ & 0.31 \\
\hline 2 & $\begin{array}{l}{[\overline{0.17} ; \overline{0.95} ;} \\
0.28]\end{array}$ & {$[0.96 ; \overline{0.22} ; \overline{0.15}]$} & $\begin{array}{l}(0.21 ; 0.24 \\
0.95)\end{array}$ & 0.49 \\
\hline 3 & $\begin{array}{l}{[\overline{0.81} ; \overline{0.12}} \\
0.57]\end{array}$ & {$[\overline{0.08} ; 0.99 ; 0.09]$} & $\overline{0.58} ; 0.03 ; \overline{0.82}$ & 0.40 \\
\hline 4 & $\begin{array}{l}{[\overline{0.17} ; 0.50} \\
0.85]\end{array}$ & {$[0.05 ; \overline{0.86} ; 0.51]$} & $\begin{array}{l}(0.98 ; 0.13 ; \\
0.12)\end{array}$ & 0.41 \\
\hline
\end{tabular}

ent direction, even if grains 3 and 4 seem to rotate towards the $\left[\begin{array}{lll}1 & 0 & 1\end{array}\right]$ direction; however not enough grains were followed to be able to conclude a general trend. Table 2 gives the amount of rotation of the austenitic lattice with respect to the applied load. It is observed that this lattice rotation takes place from the very beginning of the loading sequence. For applied stress $<280 \mathrm{MPa}$, when the alloy is still in the elastic domain, rotation angles are small and quite similar for all grains. But as soon as the martensitic transformation starts in grain 2, its rotation increases twice as fast as that for grains 3 and 4, which remain in the elastic regime. Almost at the same time, grain 1 starts to transform too, and its rotation angle stays within the same order of magnitude as grain 2 .

At a greater stress level, all grains transform, and significant but different lattice rotations are observed in all cases. A more than one to three ratio is observed between grain 1, which experiences the larger rotation, and grain 4, which presents the smallest one. One may conclude that the amount of heterogeneity increases when the phase transformation evolves.

During unloading, as presented Fig. $4 \mathrm{~b}$, it is observed that these grains rotate back towards their initial position. However, the reverse rotation is not complete: a small residual misorientation remains; its magnitude varies between $0.2^{\circ}$ and $0.5^{\circ}$, as mentioned in Table 2 . This plastic residual orientation appears less sensitive to the crystallo-

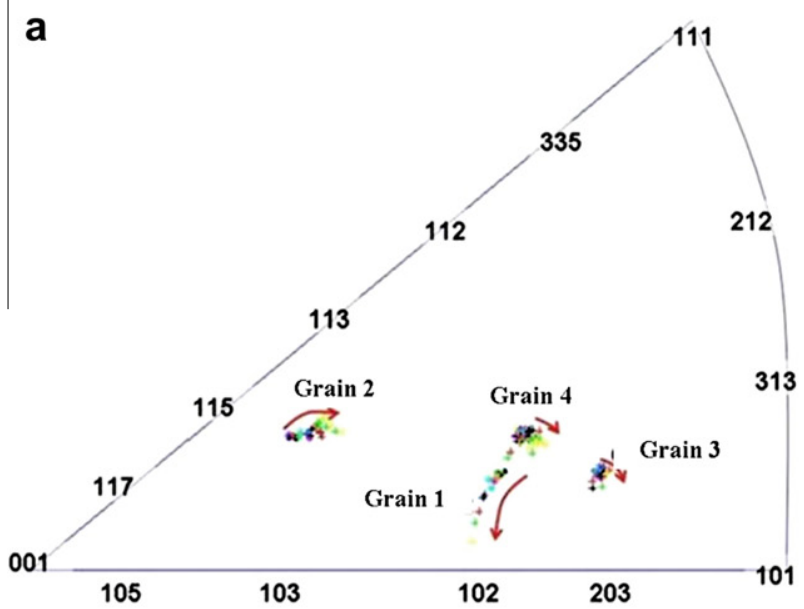

b

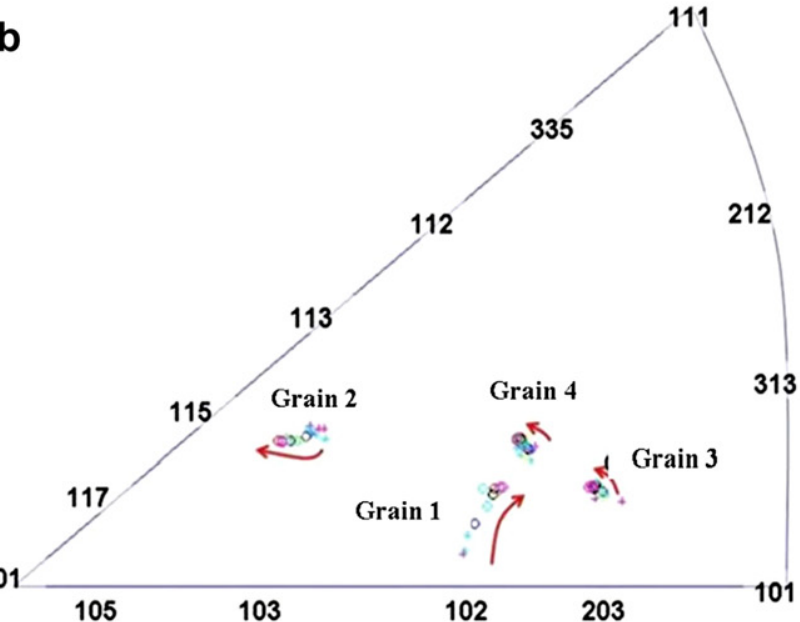

Fig. 4. The change in load axis orientation of the austenite in grains 1-4 determined from the 3DXRD method during (a) loading and (b) unloading. 
Table 2

Average rotation of the tensile direction in comparison with the crystal axis.

\begin{tabular}{lllllll}
\hline \multicolumn{2}{l}{ Macroscopic loading } & & \multicolumn{4}{l}{ Grain rotation $\left(^{\circ}\right)$} \\
\cline { 5 - 6 } \cline { 5 - 6 } Stress $(\mathrm{MPa})$ & Strain $(\%)$ & & 1 & 2 & 3 & 4 \\
\hline 300 & 0.6 & & 0.5 & 0.5 & 0.3 & 0.4 \\
360 & 1.3 & & 1 & 1 & 0.5 & 0.5 \\
410 & 3.0 & & 1.9 & 1.5 & 0.6 & 0.6 \\
430 & 3.7 & & 2.9 & 1.8 & 1 & 0.8 \\
445 & 4.5 & & 3.8 & 2.0 & 1.8 & 1.3 \\
465 & 5.4 & & 4.9 & 2.5 & 2 & 1.4 \\
0 (unloaded) & & 0.3 & 0.4 & 0.5 & 0.2 \\
\hline
\end{tabular}

graphic than to the elastic orientation. The origin of this residual misorientation may be related to internal stresses and/or to the presence of retained martensite [15].

As the grains orientation is modified, the Schmid factors are also likely to vary. Knowing the crystallography of the martensite variants, the initial parent phase lattice orientation and the rotation undergone by each grain during the transformation, the evolution of the maximum Schmid factor during a loading sequence was determined for the four grains analysed. These evolutions, presented in Fig. 5, are very small; the maximum Schmid factors remain almost constant in the four grains analysed. The lattice rotation effect even slightly decreases the Schmid factor for grain 2 . The larger increase is observed for grain 1. Therefore, the grains do not seem to rotate to increase their Schmid factor and ease the martensite formation.

\subsubsection{Sub-grain formation}

Fig. 6 focuses on the detailed orientation evolution of grain 2 during the loading and unloading sequence. This grain is chosen because it is among the first to transform. Upon loading (Fig. 6a), a single diffracting domain is observed during the elastic regime, and the rotation of the austenite lattice increases slowly to $0.75 \pm 0.25^{\circ}$. At $300 \mathrm{MPa}$, the formation of two different diffracting domains (represented by the two green dots) is observed, which corresponds to the formation of two distinct orientations within the parent phase. They are misoriented by a $0.5^{\circ}$ angle; this value is larger than the measurement uncertainty. These sub-domains appear at the same time as the first martensite variant. One may assume that the formation of this variant splits the austenitic grain into two austenitic sub-domains. The number of austenitic diffraction spots increases continuously with the applied load. At the maximum imposed load, five parent phase diffracting domains are observed for grain 2, and the misorientation between these sub-domains reaches $1.5^{\circ}$. One may conclude that the development of the transformation and the formation of martensite plates inside an austenitic grain results in a distribution of the parent phase lattice in many sub-domains. The same trend is observed in each of the four grains analysed in this study. The number of austenitic diffracting sub-domains and their orientation dispersions are summarized in Table 3. It is noticed that grain 4, which experiences the smallest rotation (see Table 2) also presents the largest number of sub-domains and the maximum rotation dispersion (up to $2.2^{\circ}$ ). In contrast, the smallest number of sub-domains and the smallest dispersion are observed in grain 1 , which is the one experiencing the larger rotation. This seems to indicate that a direct relation between these characteristics does exist.

Upon unloading, Fig. $6 \mathrm{~b}$ shows that the five subdomains formed during the loading sequence slowly merge into one single domain. At $400 \mathrm{MPa}$, four different austenitic diffracting domains are still observed; at $345 \mathrm{MPa}$, three domains remain visible; and at $300 \mathrm{MPa}$, the grain 2 has recovered a single austenitic diffracting domain. This domain continues to rotate up to the end of the unloading sequence, coming very close to the initial crystal orientation of this grain; the final misorientation is only $0.4^{\circ}$. In conclusion, the 3DXRD measurements have pointed out that the austenite orientation varies during loading and is reverted upon unloading; a small residual rotation is

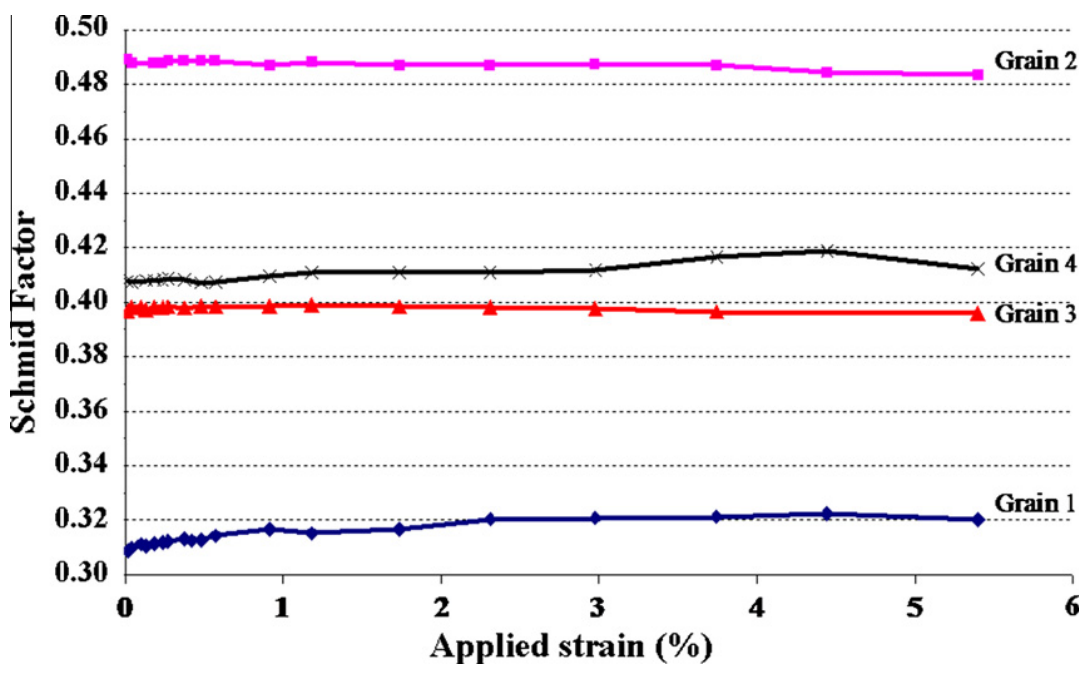

Fig. 5. Influence of crystal lattice rotation on the evolution of the maximum Schmid factors inside the four grains considered. 


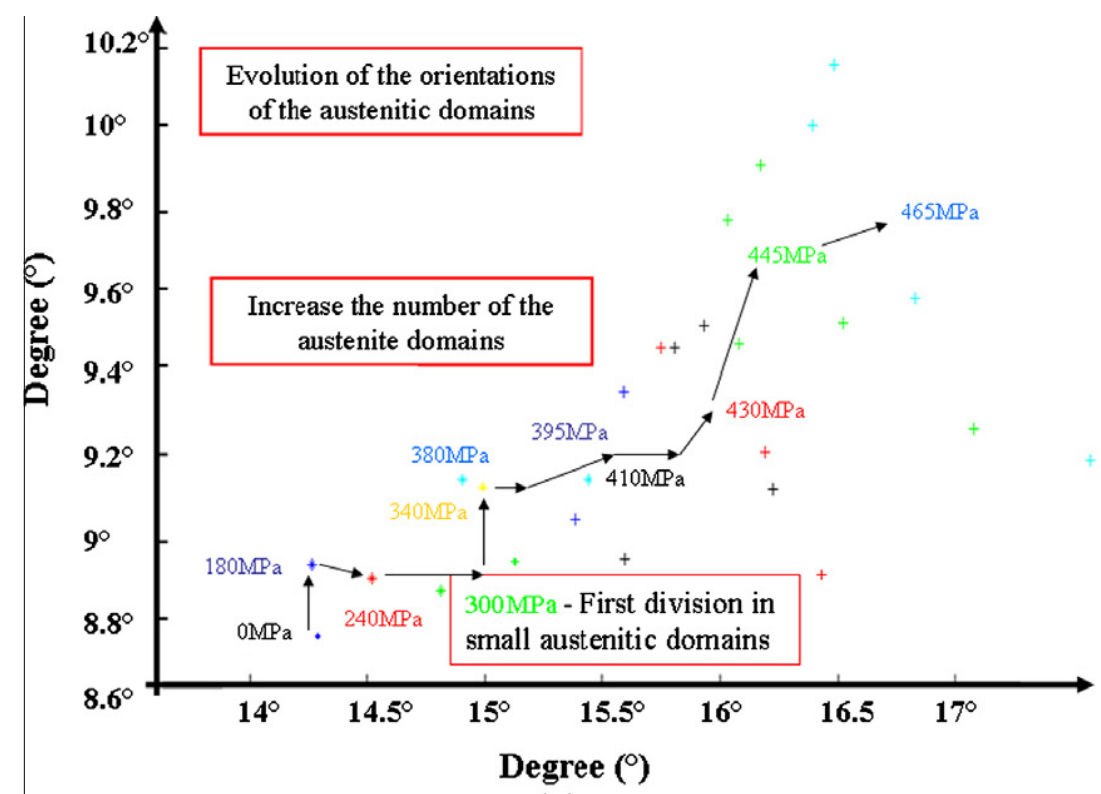

(a)

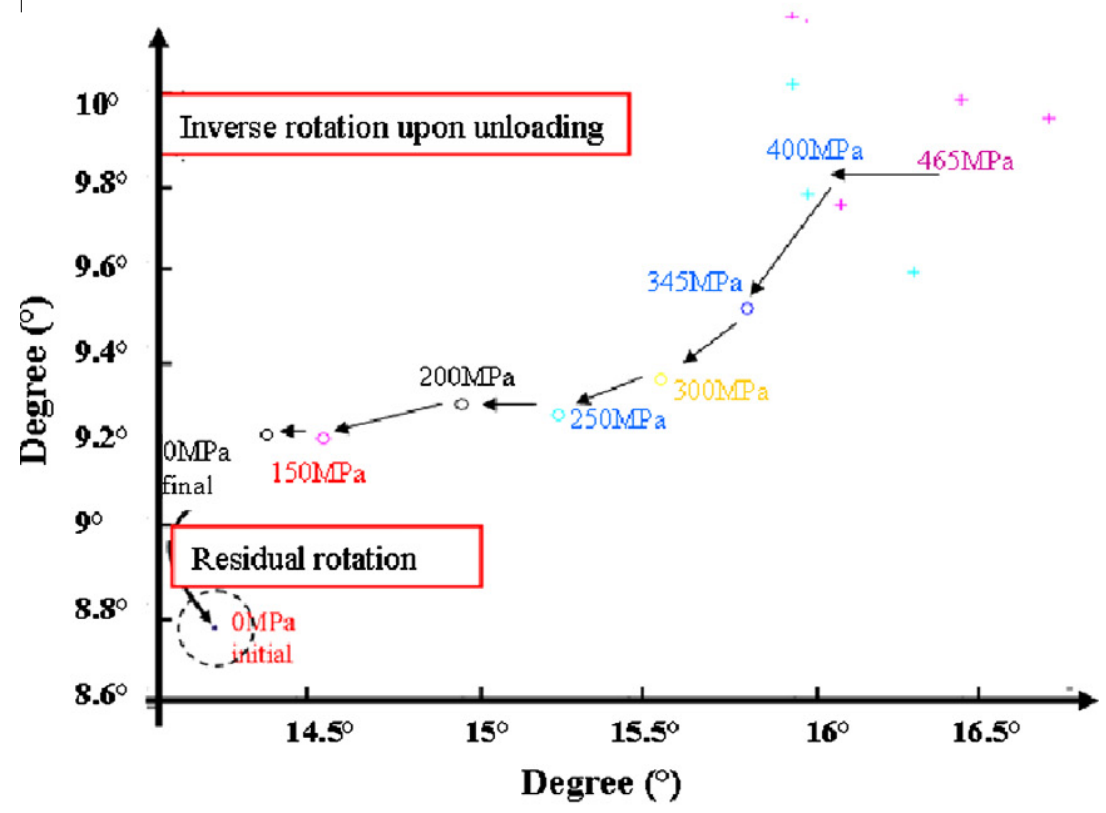

(b)

Fig. 6. (a) Parent phase lattice rotation determined in grain 2 during (a) loading and (b) unloading. Mean value evolution of all the angular positions of the diffracting sub-domains observed for a given loading step. In (b) the dashed circles represent a measurement uncertainty of $\pm 0.25^{\circ}$.

observed. As the martensitic transformation occurs, it is observed that the initial austenite orientation splits into several sub-domains of various orientations. One may assume that this is strongly related to the formation of martensite variants which "divide" the grain. To verify the localization of the sub-domains, microdiffraction experiments were carried out.

\subsection{Orientation map within a grain (Laue microdiffraction results)}

The previous section highlighted the grain behaviour. With Laue microdiffraction, the behaviour at the micron scale can be analysed inside the grain. The overall behaviour is presented in Fig. 7; the deformation is obtained from cross-heads' displacement. In this experiment, as the grain size is almost the same order of magnitude as the sample dimensions, the behaviour is closer to single crystal than polycrystal behaviour. Fortunately, this difference has no real influence for the microstructural analysis.

As mentioned in Section 2.3, these measurements give access to the three Euler angles. In the following, for simplicity, as the three angles give similar information, only mapping with the $\theta$ angle will be presented. Fig. 8 presents the different maps obtained during the loading sequence, from $0 \mathrm{MPa}$ to $120 \mathrm{MPa}$ (Fig. 8a-d), and during unloading 
Table 3

Major results obtained for transformation in the four grains considered by 3DXRD method.

\begin{tabular}{|c|c|c|c|c|}
\hline & \multicolumn{4}{|l|}{ Grain } \\
\hline & 1 & 2 & 3 & 4 \\
\hline $\begin{array}{l}\text { Stress when the first domain division } \\
\text { appears (MPa) }\end{array}$ & 340 & 300 & 360 & 360 \\
\hline Transformation order & 2nd & 1 st & $3 \mathrm{rd}$ & $3 \mathrm{rd}$ \\
\hline \multicolumn{5}{|c|}{ No. of austenitic domains (maximal dispersion) } \\
\hline At $360 \mathrm{MPa}$ & $\begin{array}{l}2 \\
\left(0.3^{\circ}\right)\end{array}$ & $\begin{array}{l}2 \\
\left(0.5^{\circ}\right)\end{array}$ & $\begin{array}{l}2 \\
\left(0.6^{\circ}\right)\end{array}$ & $\begin{array}{l}4 \\
\left(0.6^{\circ}\right)\end{array}$ \\
\hline At $410 \mathrm{MPa}$ & 1 & $\begin{array}{l}4 \\
\left(0.7^{\circ}\right)\end{array}$ & $\begin{array}{l}3 \\
\left(0.8^{\circ}\right)\end{array}$ & $\begin{array}{l}5 \\
\left(1.1^{\circ}\right)\end{array}$ \\
\hline At $430 \mathrm{MPa}$ & 1 & $\begin{array}{l}4 \\
\left(0.8^{\circ}\right)\end{array}$ & $\begin{array}{l}3 \\
\left(1.0^{\circ}\right)\end{array}$ & $\begin{array}{l}6 \\
\left(2.0^{\circ}\right)\end{array}$ \\
\hline At $445 \mathrm{MPa}$ & 1 & $\begin{array}{l}4 \\
\left(0.9^{\circ}\right)\end{array}$ & 1 & $\begin{array}{l}7 \\
\left(2.2^{\circ}\right)\end{array}$ \\
\hline At $465 \mathrm{MPa}$ & 1 & $\begin{array}{l}5 \\
\left(1.5^{\circ}\right)\end{array}$ & 1 & $\begin{array}{l}6 \\
\left(1.8^{\circ}\right)\end{array}$ \\
\hline
\end{tabular}

(Fig. 8e and f). In these maps, white areas are non-indexed zones, corresponding to martensite plates, underlined with white ellipses. Before loading (Fig. 8a), a strong local heterogeneity, up to $1^{\circ}$ of misorientation, is observed. A similar heterogeneity is obtained for maps using $\varphi$ and $\psi$ Euler angles.

For a $50 \mathrm{MPa}$ applied stress, the sample is still in the elastic regime (see Fig. 7); the mean $(\varphi, \theta, \psi)$ value has changed compared with the initial state; this is due to a macroscopic rotation of the specimen during the first loading (as presented Fig. 8b). The existence of retained martensite variants is still observed, but the main observation is a slight reduction in the local heterogeneity of the crystalline orientation of austenite. At $90 \mathrm{MPa}$ applied stress, the stress-induced martensitic transformation begins, and the occurrence of the first stress-induced variant is observed by optical microscopy. This variant corresponds to the straight non-indexed area in Fig. 8c.
At the maximum applied stress of $120 \mathrm{MPa}$, the size of the martensite plates has strongly increased, and only a small portion of the map can be indexed to give the austenite orientation. In addition, a read-out problem from the detector leads to the lost of any information between 5370 and $5390 \mu \mathrm{m}$ (Fig. 8d). Nevertheless a gradient of orientation is observed inside the small austenite domain, but there is not enough information to reach a conclusion. During unloading, at $70 \mathrm{MPa}$ (Fig. 8e), all the austenite volume is indexed, revealing two austenitic domains separated by a martensite plate. Inside each domain, the maximum misorientation is $\sim 0.3^{\circ}$, and between both domains, considering a mean orientation for each one, it is equal to $0.6^{\circ}$. Such an orientation difference stays within the same order of magnitude as that obtained between sub-domains in the 3DXRD experiment. This observation validates the assumption made from the analysis of the 3DXRD diffraction results. The appearance of the stress-induced martensite variant results in the formation of austenite sub-domains located at each side of the martensite plates. By comparison with Fig. 8b, the lattice orientation appears more homogeneous inside austenitic sub-domains during unloading than during loading.

After complete unloading, the austenite lattice orientation seems homogeneous in most of the surface analysed (Fig. 8f), but some regions present a misorientation similar to that determined before the loading sequence, and a small plate of martensite is observed with the same orientation as in Fig. 8a. In order to compare in a quantitative way the results obtained using the 3DXRD technique and Laue microdiffraction, the average values of Euler angles $(\varphi, \theta$, $\psi$ ) were determined for each loading and unloading step. The orientation matrix $U$ of the austenite was calculated from the knowledge of these three angles [33]. The accuracy of the Laue microdiffraction technique allows the observation of a rigid body rotation of the austenite lattice due to the positioning of the sample inside the grips during the

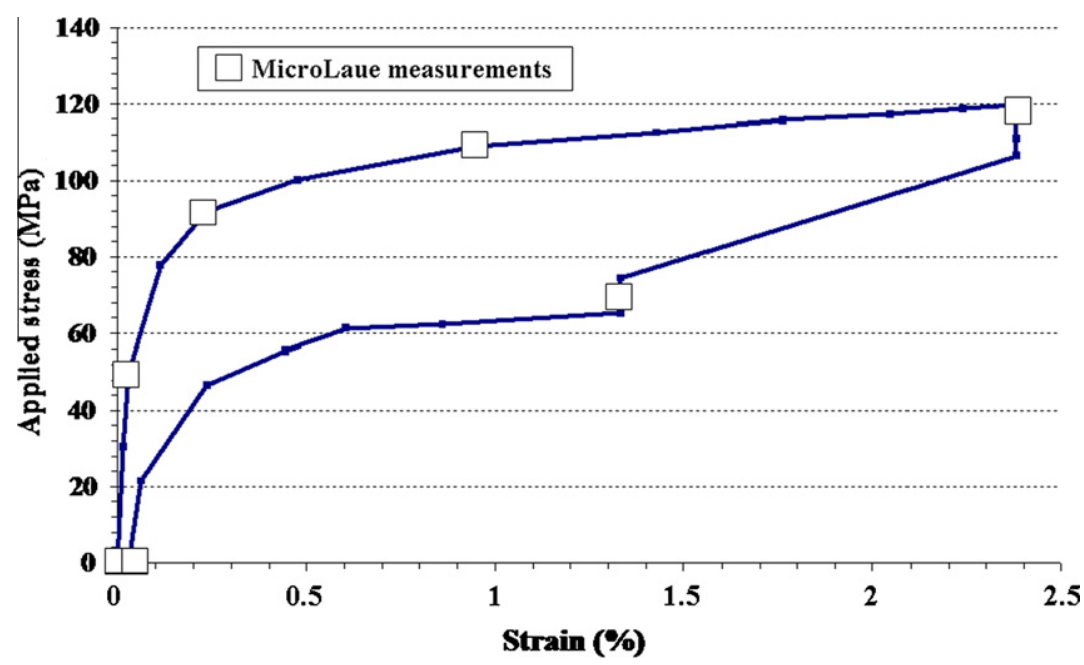

Fig. 7. Stress-strain curve of the CuAlBe superelastic sample recorded during the Laue-microdiffraction experiment. Square dots indicate the analysis points. 


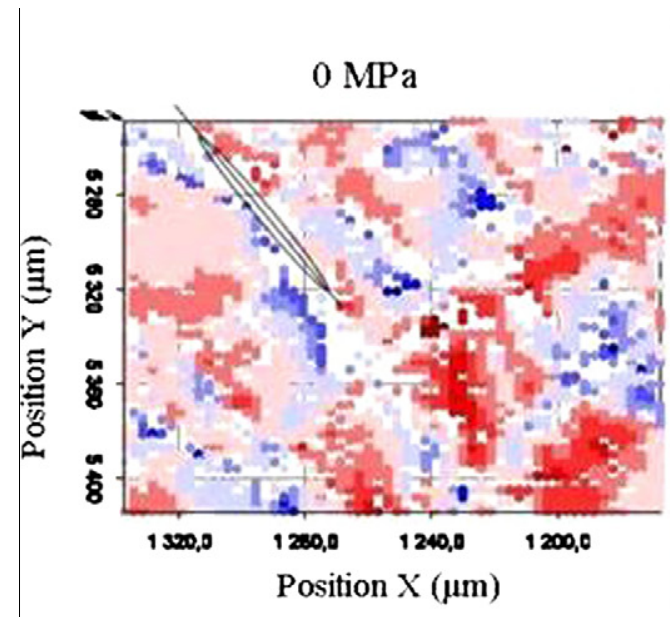

(a)

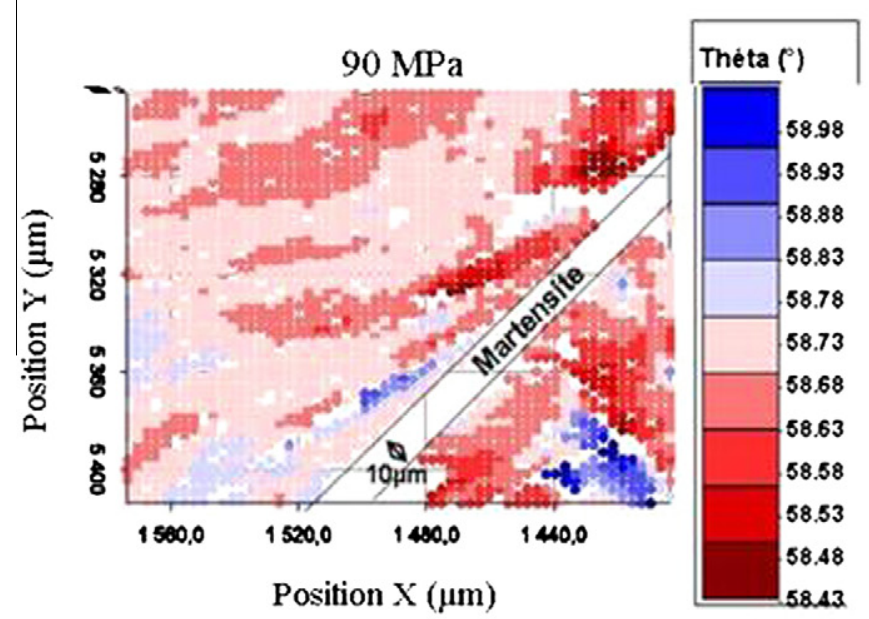

(c)

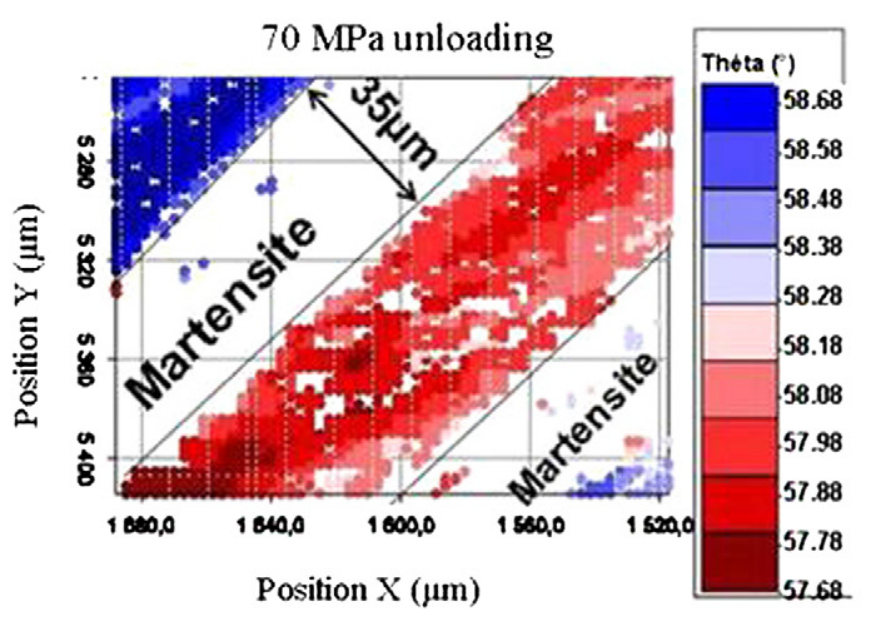

(e)

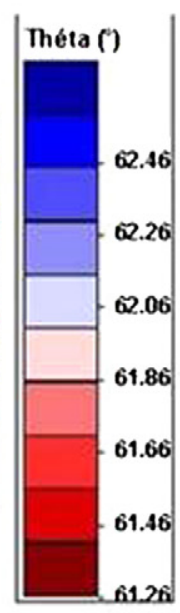

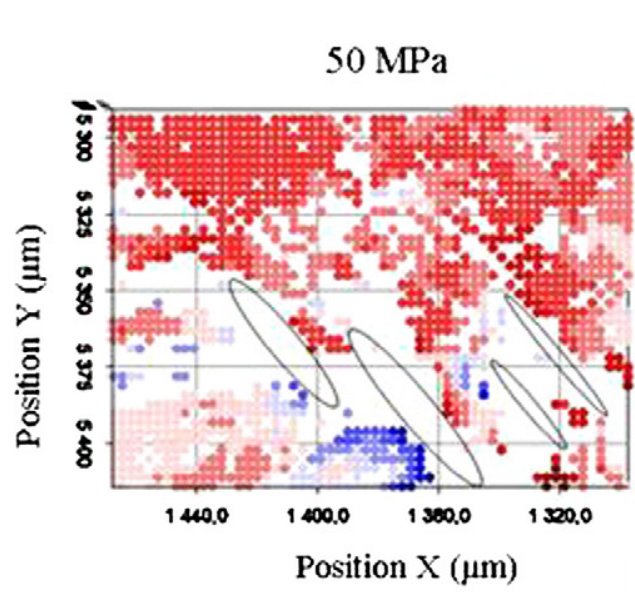

(b)

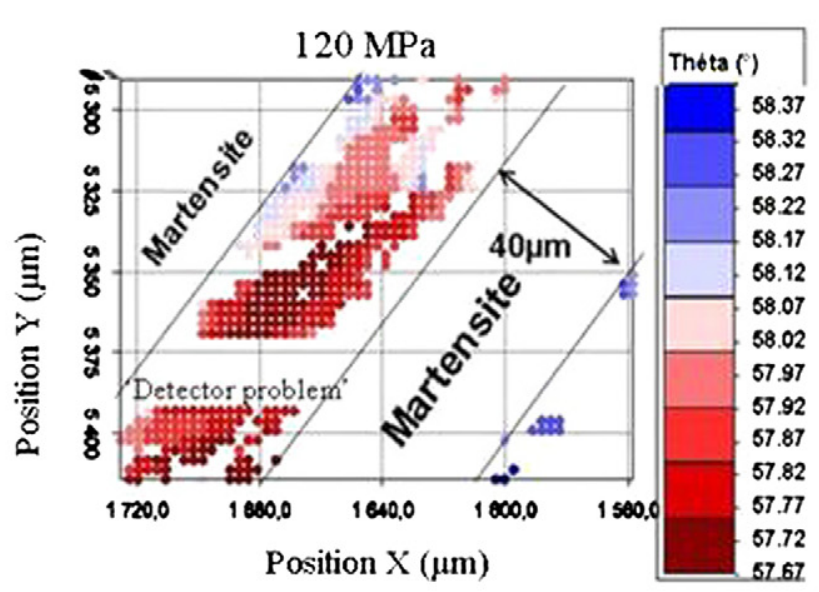

(d)

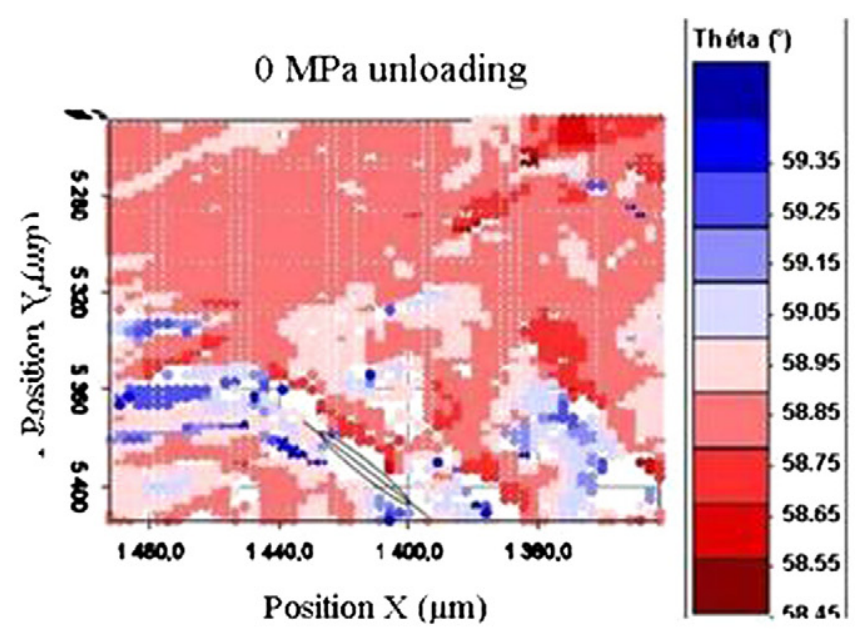

(f)

Fig. 8. Map of the local orientation ( $\theta$ angle) of the crystal lattice of austenite as a function of loading stress: (a) initial map at zero stress; (b) 50 MPa; (c) $90 \mathrm{MPa}$; (d) $120 \mathrm{MPa}$ (only a limited portion is indexed owing to the formation of large amount of stress-induced martensite and the occurrence of a detector problem); (e) $70 \mathrm{MPa}$ during unloading; (f) after complete unloading at zero stress. The small white ellipse indicates a retained martensite variant. The white area corresponds to stress-induced martensite.

first stage of loading. Then, considering the mean orientation at $50 \mathrm{MPa}$ as a reference, a maximum mean rotation angle of $2.5^{\circ}$ was measured at $120 \mathrm{MPa}$; this is within the same order of magnitude of rotation value observed in 
Table 4

Rotation and dispersion (differences between maximum and minimum rotation values).

\begin{tabular}{|c|c|c|c|}
\hline \multicolumn{2}{|c|}{ Macroscopic loading } & \multirow[t]{2}{*}{$\theta$ angle $\left(^{\circ}\right)$} & \multirow[t]{2}{*}{ Dispersion $\left({ }^{\circ}\right)$} \\
\hline Stress $(\mathrm{MPa})$ & Strain $(\%)$ & & \\
\hline 0 & 0 & 61.9 & 1.2 \\
\hline 50 & 0.02 & 58.8 & 0.8 \\
\hline 90 & 0.22 & 58.8 & 0.55 \\
\hline \multirow[t]{2}{*}{120} & 2.4 & 57.7 & 0.5 \\
\hline & & 58.1 & - \\
\hline \multirow[t]{2}{*}{70} & 1.31 & 58.6 & 0.3 \\
\hline & & 58 & 0.4 \\
\hline 0 & 0.02 & 58.8 & 1.1 \\
\hline
\end{tabular}

the 3DXRD experiment. During the unloading sequence, the austenite experiences an inverse rotation, the rotation angle being $1.3^{\circ}$ at $70 \mathrm{MPa}$. No residual rotation is observed in this experiment; the unloading orientation is very closed to the initial orientation (considering it takes place at $50 \mathrm{MPa}$ to account the rigid body rotation), whereas the residual rotation was $\sim 0.4^{\circ}$ in the 3DXRD experiment. This difference can be due to the grain orientation, which is not the same in both cases. It can also be related to the difference in data acquisition techniques: Laue microdiffraction analyses a small volume at the free surface $\left(\sim 0.0004 \mathrm{~mm}^{3}\right)$ compared with the 3DXRD method, which considers embedded grains within the bulk and samples of a larger volume $\left(0.032 \mathrm{~mm}^{3}\right)$. Moreover, the maximum strain reached was not the same in both experiments.

Table 4 summarizes the evolution of the rotation of the austenite and differences between maximum and minimum orientation values (dispersion). A decrease in the mosaïcity of the austenite with the applied stress was observed, and an increase back to the initial value during unloading. This result was confirmed by the evolution of the lattice curvature measured on a single crystal using a hard X-ray diffractometer [34].

\section{Discussion}

Experiments performed in this study establish that the stress-induced martensitic transformation in a $\mathrm{Cu}_{74} \mathrm{Al}_{23} \mathrm{Be}_{3}$ SMA induces rotation of the crystal lattice of the austenite parent phase. Fig. 4 clearly highlights this rotation. The detailed results presented for grain 2 in Fig. 6 show that the number of austenite diffracting sub-domains increases during the transformation. Similar results were obtained by Poulsen et al. on a polycrystal of aluminium deformed plastically at room temperature [21]. They showed that the magnitude of grain rotation depends on the initial orientation of the grains. Only a few crystallographic orientations were investigated in the present work, so it is difficult to give a definite statement. Nevertheless, the crystallographic orientation seems to have an influence for SMA too.

Poulsen et al. observed also that grains "split" into several orientations at higher strains, corresponding to sub-grain formation [21]. In aluminium, rotation and subgrain formation are irreversible phenomena. For $\mathrm{CuAlBe}$ SMA, Fig. 6 demonstrates the reversibility of the lattice rotation and shows that the austenite diffracting sub-domains eventually merge into one single domain to recover the initial crystal orientation at the end of the reverse transformation. This is a major difference between the two deformation mechanisms of plasticity and stress-induced transformation. In SMA, the occurrence of sub-domains can be related to the formation of martensite plates inside the initial austenite grains, as shown in Fig. 8. The austenite orientation differs on each side of a martensite variant. It clearly indicates that this misorientation takes its origin in the martensite variant occurrence itself, and is not related to the amount of strain that takes place in austenite. Crystal rotation values obtained from the microdiffraction analysis are consistent with the 3DXRD experiment. These observations firmly establish the existence of a grain rotation associated with stress-induced martensitic transformation and produce the set of results displayed in Tables 2 and 3. These are summarized as follows:

(1) The austenite crystal lattice undergoes a rotation of several degrees when a stress-induced martensite transformation takes place. The rotation angle depends on the crystallographic orientation.

(2) This rotation comes along with the occurrence of a reversible sub-grain formation mechanism. Within a grain, the number of austenite diffracting subdomains increases with the progress of the transformation.

(3) Austenite lattice rotation and sub-grain formation are reversible phenomena. The initial austenite crystal lattice orientation was recovered during the reverse transformation.

These interpretations are reinforced by previous data sets based on laboratory XRD measurements in a similar SMA. Using a single crystal analysis methodology, the full local stress tensor was determined in the austenite for individual grains embedded into a polycrystalline sample [9]. It appears that the local stress state increases with the applied load during the elastic regime, but remains almost constant as the martensitic transformation takes place within the analysed grain. Considering elasticity is the only active deformation mechanism in austenite before it transforms to martensite, it can be concluded that the elastic deformation is constant in austenite during the transformation. In the present investigation, only a small lattice rotation was recorded in the elastic loading regime. Such a small rotation fully agrees with the low value taken by elastic deformation. Therefore the main part of austenite grain rotation takes place during the martensitic transformation regime. Thus the rotation found in this work is not related to the deformation which takes place in austenite, but it is required to accommodate the strain incompatibility due to the austenite-martensite interface formation. This was 
first assumed by Sittner et al. [15] in a $\mathrm{Cu}-\mathrm{Al}-\mathrm{Zn}-\mathrm{Mn}$ SMA; during stress-induced transformation, they observed a widening of the austenite diffraction peak. They correlated it to a decreasing size of coherent diffracting blocks and to the stress redistribution between austenite and martensite.

These analyses are consistent with the observation that the number of sub-domains formed is large in grains presenting only a small rotation. A transformation occurring with the formation of few sub-domains is likely to be associated with the formation of large martensitic plates inside the grain. Existence of such large martensite domains will require large rotation to accommodate the amount of strain incompatibility in this case. As a consequence, the rotation found in this work must be strongly size dependent, with large rotation related to coarse grain size and small rotation related to small grain size. Additional experiments are in progress to asses this assumption.

\section{Conclusion}

In this study, a unique multi-scale data set was obtained using two novel microdiffraction techniques, pointing out the evolution of crystallographic orientation within individual grains during an in situ tensile test. It was found that:

1. During loading, the average orientation of a grain is rotating; the rotation angle is larger during the elastic regime than in the transformation regime. Moreover, it is dependent on the initial grain orientation.

2. Upon unloading, the reverse rotation is observed with a small residual misorientation.

3. During the martensitic transformation, the austenitic grains split into sub-domains of different orientations, located from each side of the martensite plates. These sub-domains merge together upon unloading.

4. These measurements will offer a good database for modelling, in particular to validate micro-macro modelling, where one has to define a representative volume element.

\section{Acknowledgements}

The authors thank the directors of ILL and ESRF for their financial support as well as the teams of the ID11 and BM32 beamlines for their technical support. The authors also thank A. Eberhardt, D. Bouscaud, R. Pesci, M. Wary and R. Berrahmoune for their collaboration throughout these experiments. The authors are grateful to T. Buslaps (ESRF Grenoble) for useful help in 3DXRD experiments and to S. Schmidt for assistance with Grainspotter.

\section{References}

[1] Otsuka K, Ren X. Prog Mater Sci 2005;50:511.

[2] Stoeckel D, Pelton A, Duerig T. Eur Radiol 2004;14:292-301. doi:10.1007/s00330-003-2022-.

[3] Hülsmann M, Jodway B. Int Endod J 2006;39:71

[4] Bhattacharya K, Kohn RV. Acta Mater 1996;44:529.

[5] Zhang W, Jin YM, Khachaturyan AG. Acta Mater 2007;55:565.

[6] Patoor E, Eberhardt A, Berveiller M. J Phys IV 1996;6:277.

[7] Brinson C, Schmidt I, Lammering R. J Mech Phys Solids 2004;52:549.

[8] Gall K, Sehitoglu H, Maier HJ. Metall Trans 1998;29-3:765.

[9] Kaouache B, Inal K, Berveiller S, Eberhardt A, Patoor E. Mater Sci Eng 2006;A438:773.

[10] Kaouache B, Berveiller S, Inal K, Eberhardt A, Patoor E. Mater Sci Eng 2004;A378:232.

[11] Krishnan RV, Brown LC. Metall Trans 1973;4:423.

[12] Otsuka K, Sakamoto H, Shimizu K. Acta Metall 1979;27:585.

[13] Schroeder TA, Wayman CM. Acta Metall 1979;27:405.

[14] Otsuka K, Wayman CM, Nakai K, Shimizu K. Acta Metall 1976;24:207.

[15] Sittner P, Lukas P, Neov D, Daymond MR, Novak V, Swallowe GM. Mater Sci Eng 2002;A324:225.

[16] Morin M, Baron MP. In: Proceedings of PTM'99 (JIMC-3); 1999. p. 1028.

[17] Jimenez-Melero E, Van Dijk NH, Zhao L, Sietsma J, Offerman SE, Wright JP, et al. Scripta Mater 2007;56:421.

[18] Offerman SE, Van Dijk NH, Sietsma J, Zhao L, Lauridsen EM, Margulies L, et al. Nucl Instrum Methods Phys Res 2006;B246:194.

[19] Jakobsen B, Lienert U, Almer J, Poulsen HF, Pantleon W. Mater Sci Eng 2008;A483-484:641.

[20] Zuniga HF, Rios Jara D, Lovey FC, Guenin G. J Phys IV 1995;5:171.

[21] Poulsen HF, Margulies L, Schmidt S, Winther G. Acta Mater 2003;51:3821

[22] Reichert H, Honkimäki V, Snigirev A, Engemann S, Dosch H. Physica B 2003;336:46.

[23] Schmidt S, Jensen DJ. Arch Metall Mater 2005;50:181

[24] Poulsen HF. Springer tracts in modern physics. Berlin: Springer Verlag; 2004. p. 205.

[25] Lauridsen EM, Schmidt S, Suter RM, Poulsen HF. J Appl Crystallogr 2001;34:744.

[26] Poulsen HF, Nielsen SF, Lauridsen EM, Schmidt S, Suter RM, Lienert U, et al. J Appl Crystallogr 2001;34:751.

[27] Wright JP. <http://fable.wiki.sourceforge.net/imaged11>.

[28] Schmidt S. <http://fable.sourceforge.net/index.php/Grainspotter>.

[29] Martins RV, Margulies L, Schmidt S, Poulsen HF, Leffers T. Mater Sci Eng 2004;A 387:84.

[30] Tamura N, http://xraysweb.lbl.gov/microdif/.

[31] Chung JS, Ice GE. J Appl Phys 1999;86:5249.

[32] Montecinos S, Cuniberti A. J Alloys Compd 2008;457:332.

[33] Bunge HJ, Esling C. Quantitative texture analysis. Frankfurt am Main: Deutsche Gesellschaft für Metallkunde; 1982

[34] Malard B. PhD thesis ENSAM; 2008. <www.pastel.paristech.org>. 